also exists, but in them it has lost all semblance of its $\mid$ in insect organizations to the repetition of similar original nature, and is solid and replete with blood
vessels. But, most curious of all, there is in the brain of Inan himself a small organ about the size of a hazel nut,
called the pineal gland, the function of which has always been a puzzle to physiologists, and which was ways been a puzzle to physiologists, and which was
supposed by Descartes to be the seat of the soul. Comparative anatomy has shown that this gland is probafrom some remote ancestor of the vertebrates, in whom

it was developed into a true eye.

There exists a certain connection between the power
of seeing and the capacity for producing light possessed tention to the manifestation of this latter power among insects, where it is best known, but notices only some
of the more curious phenomena regarding fishes. There are present on some fishes curious eye-like bodies more
or less connected with the muciferous canal, and though or less connected with the muciferous canal, and though
the original opinion that they were acessory eyes is still entertained by some naturalists, yet later researches have, they are certainly luminous organs, and are espive in the depths of the sea are comparatively unknown as they only ascend to the surface of the ocean by some density of the water in which they are accustomed to

On this account it is difficult to determine their real characteristics, and our knowledge of them is mainly
confined to the few specimens brought up by the dredge and particularly those obtained by the Challenger expedition. The light of the sun penetrates the ocean
only to the depth of 200 fathoms, and below this the sea fishes the eyes have altogether disappeared. But others, in which they are still well developed, are en-
dowed in addition with organs capable of shedding dight, and evidently under the control of the animal.
As a rule, the coloring of these fishes is pink, silvery, or black relieved by dashes of scarlet, and the effect of
an irradiation by the sudden flashing out of a light must be very striking. The largest of these luminous
organs yet discovered is directly under the eye of the organs yet discovered is directly under the eye of the
fish, so that the animal is, as it were, provided with a
bull's-eye lantern. Others have a pair of similar very bull, so the lantern. Others have a pair of similar very
large organs in the tail, and still others have developed them at the end of long filaments springing from the With regard to the production and perception of
sound among the lower animals, we are told that neither the protozoa nor coelenterata and very few of the mollusea are known to produce sound. There is one
genus of crab which can make a harsh, jarring noise by rubbing a sort of file or rasp on its claw against a
ridge on the limb, and some of the lobsters can do the same by rubbing one part of the antennæ against
another, but the power of producing sound among the
crustaceans, curiously enough, seems entirely disproportionate to the development of their hearing appaquainted with the sounds produced by many insects,
such as crickets, grasshoppers, katydids, etc., and these sounds are made in various ways, by the wings or by
the breathing tubes, which in insects are distributed along the sides of the body, or by rubbing one part of
the body against another. In many cases the power the body against another. In many cases the power
of making sounds is confined to the male. A house fly
hums on $\mathrm{F}$, and to do so vibrates its wings 21,120 times in a minute, and the bee, which hums on A, moves hums on $E$ sharp, vibrates its wings only 19,800 times
a minute. Exeept for these slight changes, due solely to fatigue, the sounds produced by the wings of each
variety of insect are unalterable, but those emitted by the spiracles or breathing tubes seem to be more or
less under the control of the will, and in this respect resemble what we call a voice. One insect, the cockchafer, not only hums with its wings, but also produces
a sound which is peculiarly voicellike, as right behind the opening to each breathing tube there is a horny
process something like a tongue, which is made to vibrate by respiration, and thus emit a humming noise. brate by respiration, and thus emit a humming noise.
The auditory organs among the lower animals are
situated in various parts of the body, and range through many degress of complexity, from an apparatus so simple that it is doubtful whether it is intended
to recive an impression of sound or simply to record plentifully supplied with nerves. Among the higher crustaceans the auditory sac is usually at the base of
the small antennæ, though in one of the lower forms the two ears are situated in the tail. Strychnine is ters, and one naturalist took advantage of this to prove that crustaceans are really possessed of a sense of hear-
ing, by placing some shrimps in sea water containing strychnine, under which treatment the shrimps exhib. ited an extreme sensitiveness to the sfightest noises.
It has been demonstrated by numerous experiments that, in some insects at any rate, the organs of hearing are situated in the antenne, but other observations
have seemed to point to a different conclusion, and the highest authorities differ on the subject. The infer-
ence from the various recorded observations seems to be that the sense of hearing is not always confined to one spot, and that while in some insects it resides in the antenne alone, in others it is also situated in other
parts of the body. In grasshoppers, for instance, two oval, drum-like structures in the legs have been proved
to be auditory apparatus. In true locusts the organ to be auditory apparatus. In true locusts the organ
of hearing is situated in the first segment of the abdomen. The as an of wings, in place of th $A$ two possessed by other insects,
the hind wings being represented by two curlous little
club-like processes. Yet these minute organs reeive club-like processes. Yet these minute organs receive
the largest nerve in the wnole body of the fly, with the one exception of that which supplies the eyes, and are
of the most complicated nature. Special sense organs occur also in the wings of other insects, and there is
much reason for regarding all of these curious structures as organe of hearing, though many naturalists settled. That in the same creature there should be
various organs of hearing, constructed on different principles and situated in different parts of the body, \begin{tabular}{l|l} 
duce red, and, as the number increases, the color passes \\
into orange, then yellow, green, blue, and violet. But \\
between 40,000 vibrations in a second and 400 millions
\end{tabular} ing the impression. Yet between these limits any
number of sensations may exist. We have five senses and sometimes fancy that no others are possible. Bu The seat of the sense of smell in the lower animals is is probable that no such sense exists. In insects there is good reason for supposing that the sense of
smell resides partly in the antennæ and partly in the palpi, and there are some facts which would appear to dors and the palpi to others. Though it is in every way probable that a sense of taste, to assist them in the selection of their food, is als, yet little or nothing is known as to the organ
wich exercise this function. Jelly fish, for instance, whe quickly affected by any change in the medium
which they inhabit, and sink below as soon as it begins to rain, but it is iupossible to say what sense it is which
in affected. Insects evidently possess a sense of taste nts have begun to feed on honey mixed with strych ine or alum, and rejected the food as soon as they dis assiduously to remove the taste. Quinine or glycerine on account of the taste, and not from any instinctive apprehension of the injurious results, for Torel found
that ants could not detect a mixture of phosphorus with their honey and swallowed it without suspicion, though inute pits, furnished with delicate hairs, and found on the tongue and maxillæ of all insects, are probably
he organs of taste. Among the lower animals the outer skin is often very
ensitive, and though the minute anatomy of their organs of feeling is still undetermined, yet it is known nerve fibrils connecting with hairs, bristles, or ciliæ.
All the senses of which we have spoken correspon nore or less to those possessed by man, but among the nore or less to those possessed by man, but among the
organg evidently sensory, but the functions of which organs, evidently sensory, but the functions of which are often of considerable complexity, more or less fully
curnished with nerves, and evidently of great impor ance to the creature. The immensely diversifed
bristles and cirrhi of many worms, the curiously formed ppendages of the skin on many insects, the whole arly those connected with the muciferous canal, the
ingular groups of hairs on some jelly fish, the bright spots around the margin of certain sea anemones, are Who, are not only the seat of the three senses, hearing,
feeling, and smell, but it appears probable from the
singular variety of organs with which they are furnishdhat they perform still other functions. Sir John
ays: "Some of these antennæ organs, though obviously organs of sense, seem to have no special
adaptation to any sense of which we are cognizant." It is now a number of years since the author an
It nounced his conclusion, fortified by many ingenious Which we have in common there is a marked difference nsects and our own. It appears that with regard to
sound some of the lower animals are apparently no knowledge. Ants, for instance, make no noise audino knowledge. Ants, for instance, make no noise audi-
ble to us, yet they have rasp-like organs, similar to sound, and they have also, according to the observa-
ions of the author, an auditory apparatus in the legs imilar to that of the orthoptera. Some experiment hile they took no notice whatever of ordinary noises and fine file immediately excited their attention. "From the fact,", says our author, " that the power of
producing sounds audible to us is scattered among so no shrill, I am disposed to suspect that many insects o shrill, I am disposed to suspect that many inse
sually regarded as dumb really produce soun
hich, however, are beyond our range of hearing." Sir John also relates again the interesting experiSir John also relates again the interesting experi-
ments made by him some time ago to prove that some
animals possess the ability to distinguish colors invisible to human eyes. He showed that ants were ex-
tremely sensitive to ray's of light whose vibrations were tremely sensitive to rays of light whose vibrations were
too rapid for us to perceive. Experiments made on
some small fresh water crustaceans, belonging to the genus Daphnia, seem to show that these also perceive he ultra-violet rays to which we are blind. In
oncluding his remarks on these subjects, Sir John "It has been shown that animals hear sounds which perceive the ultra-violet rays, which are invisible to
our eyes. "Now, as every ray of light which we can perceive
t all appears to us as a distinct color, it-becomes probaple that the ultra-violet rays must make themselves of which we can form no idea), but as different from
he rest as red is from yellow or green from violet. The woustion also arises whether white light to these insects
would differ from our white light in containing this additional color. At any rate, as few of the colors in
nature are pure, but almost all arise from the combinature are pure, but almost all arise from the combi-
nation of rays of different wave lengths, and as in such
cases the visible resultant would be composed not only ases the visible resultant would be composed not only
of the rays we see, but of these and the ultra-violet, it would appear that the color of objects and the general

"These considerations cannot but raise the reflec
"The thon how different the world may-I was going to say Sound is the sensation produced on us when the vibra-
tions of the air strike on the drum of our ear. When they are few, the sound is deep; as they increase in
number it becomes shriller and shriller; but when they reach 40,000 in a second they cease to be audible. Light is the effect produced on us when waves of light strike
on the eye. When 400 millions of millions of vibra tions of either strike the retina in a second, they proshooting ducks, and we frequently spent a week at a
time there, in a little hut on Stratton Island, built of
rough stones. half under ground. with roof made of

"Moreover, looking at the question from the other "we, wnd in animals complex organs of sense richly are as yet powerless to explain. There may be fifty
other senses as different from ours as sound is froul sight ; and even within the boundaries of our own senses there may be endless sounds which we cannot
hear, and colors as different as red from green, of which questions remain for solution. The familiar world which surrounds us may be a totally different place to
other animals. To them it may be full of music which we cannot hear, of color which we cannot see, of sensaTHE HARBOR SEAL.

$$
\text { Phoca vitulina. }
$$

By Manasseh Smith,

Most of our readers are familiar with (at least the outer covering of ) the fur seal, or Alaskan seal, as it is
now commonly called, since the world's largest supply an waters, the Antarctic region having been nearly But few people, outside of our fishermen, know
much of the habits of the harbor seal that still abounds on the Atlantic coast of North America, from the shores of Maine northward into and overlapping
the domain of the Greenland seal (P. Groenlandica) While stray specimens of the family are still occasion-
ally seen as far southward as Chesapeake Bay. At the time of the early advent of Europeans to this New Jersey coast, and congregated in large numbers
on Robin's Reef, in New York Bay, and from that fact

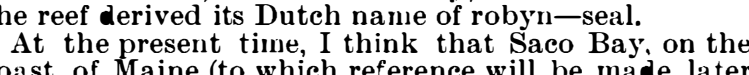
on), can be called the southern limit of their range in arge numbers; certainly they are conmparatively
arge num xtends a olong the Labrador coast and to southern
ireenland. The pinnipeds-well named fin-footed-embracing the seals and walruses, are a sub-order of the order of
Fer or carnivorous nimmals, and their life is mostly Fent in aquatic pursuits - of fish.
From what causes and through what processes they have evolutionized to so wide a variation from their
and-dwelling congeners, and whether the sea lion was volved from the African lion, or the Polar bear from are questions for whose answers I will refer the curibus reader to scientists, such as Darwin or Huxley
but that the harbor seal and say the Chesapeake Bay dog were onee one, though not since indivisible, I have
o doubt. 'The tradition among the bay men, that the Chesapeake Baydog in derived from a cross of the
Newfoundland $d o g$ with the otter will scarcely be But as we have, in popular parlance, sea lions, sea But as we have, in popular parlance, sea lions, sea
bears, sea cows, river horses, etc., I have often wonsea dog; its head bears a strong resemblance to that of a dog, minus the ears; the ery of the mature seal is
the bark, and its voice of anger the snarl and growl of a dog, while the cry of its young is an almost exact
imitation of the whine of a puppy dog. Notwithstanding its lack of education in preceding dog, and the many triek-performing, educated seals of ng knowledge, while there are few animals so quickly
and easily domesticated, or that show so strong an af Stripped of his hairy (or furry)
ction for their humer Stripped of his hairy (or furry) overcoat and of his
atty undershirt, the body of the seal displays the four egs of the dog, that were previously concealed from ligh of the dog, that were previously concealed from
knees and elbows ; and stripped of his to to beyond the he displays what might well pass, with an ordinary observer, as the skeleton of a dog, the bonts being slightly modi
fied to accommodate the diverse pursuits of the ani In other words, wide apart as is the external appearnce of the two animals, the difference between their
nternal anatomies is comparatively slight, and the otter would serve well as a connecting link between the
wo. The muscular power of the seal is enormous, their
peed in the water as marvelous as their movements on peed in the water as marvelous as their movements on
and are awkward, although the celerity with which they tumble from the rocks into the water, upon the
least suspicion of danger, is also awkward for their
would-be slayer; and the accounts of Aretic seal-hunt-
ers walking up to their prey and killine it with a club ers walking up to their prey and killinr it with a club
eem almost incredible to one whose only acquaintance ith the wary, sharp-eyed, keen-nosed harbor seal,
whose powers of sight and hearing must be far greater han those of his Arctic brethren, and his bump of cau tion more highly developed, since, abundant as they
are, it is comparatively seldom that inan can approich o as to shoot them--when they are on the land.
Some two and a half miles seaward from Prout's Neck, the point of land that forms the northeastern
boundary of Saco Bay, on the southern part of the and Bluff, the latter containing about eight acres of orass land, and, at low tide, about thirty or forty acres the latter in size. At high water, the passage between
the islands is about one-third of a mile in width. Bluff Island is uninhabited. There is a dwelling house, etc.,
on Stratton, erected some fifteen years ago. Previous the Indians, in sixteen hundred and something, destroyed the first settlenient of whites thereon. For ew sportsmen frieuds and myself. for the purpose of 
During my frequent visits to these islands I had frequent opportunities for, and spent many hours in,

tumn, and continue increasing in number early auwinter, when the herd numbers several huudred ; their favorite roosting place is on Bluff Island, but few coming ashore on Stratton. Here they remain until May, when they scatter up and down the coast, following
the fish into the bays, and even up our rivers for long the fish into the bays, and even up our rivers for long
cistances, being occasionally seen as far up the Kennetempted, doubtless, by the anadromous fish, shad, alewives, salmon, etc., that are then pushing up from the fall to their former guarters. When approaching the islands, during the time when the seals are there, I have rarely known it to fail Neck, one or more seals would appear near us fall into the wake of the boat, and escort us to the landing, and again, when we left the islands, they would see us safely to the mainland.

Shooting upon the farther side of Stratton lsland pould selcom disturb the seals on Bluff, but if a boat the latter before the boat got across, not only those in sight of the boat, but those on the opposite side who could neither see, hear, nor smell the boat. Just how the warring of danger was passed from one to another approach, and no one of us ever succeeded in killing a On the rocks there.

On one occasion, however, when several of us wer crossing the channel bet ween the islands, a seal into his neck at the base of the skull, making a hole about an inch and a half in diameter, from which the blood poured in a strean, reddening the water for immediately having toen killed so theal did not $\sin k$ could not side of it, but the man nearest was afraid to seize it lest he should be bitten, and the boat went over the seal
forcing it under, and we lost it, not having a gaff. The curious part of the story is this: The previous day I had estimated, from a partial count, that there were at least 300 seals in the herd; the day after this one was shot they return that be seen lrom either island, nor did month or so earlier than their usual time for leaving the islands.
Uudoubtedly, some of the seals, upon seeing the blood and dead body of their companion, gave the alarm the others, and the whole herd left for, safer quarters, and yet the shooting at ducks never seemed
to seriously disturb them. Of course they would all take to the water when (or rather before) the first shot was fired on Bluff Island, but many would remain in the vicinity, and occasionally one would take under a dead or wounded duck, and often within an hour
after we left Bluff Island the seal would begin to crawl after we left Bluff Island the seal would begin to crawl
out on the rocks again. I will give one more incident, showing the intelligence of the seal, that came under my personal observation. Sitting, one day, at the window of the house on Stratton Island, I observed several herring gulls (Larus argentatus) hovering over some object in the jumped into the air, evidently alarmed, but from what cause I could not imagine. Soon another and still trouble, but I could discover no reason for their alarm. Their actions puzzled me, as only one rose at a time, and none flew away, but, with the aid of a field glass, I saw that the object of attraction was a crippled duck
(Harelda glecialis), local name old squaw, whose (Harelda glucialis), local name old squaw, whose movements were very peculiar, and 1 was soon satis-
fied it was being pulled about by some other force than
that of its own feet. My first thought was that a school of large fish was the cause of all this commotion;
but, after a while, as a gull jumped into the air, I saw the head of a seal appear for an instant above the water in the place where the gull had been sitting. The mystery was now solved. Calling the attention of my ed for a while collected there.

The duck could, apparently, neither fly nor dive, but the seal, seizing it by the legs, would push it this way and that, occasionally lifting it clear of the water, and the gulls would circle around and hover close to it. come up under and attempt to seize the gull. For more the part of the seal, worthy of greater success. As he failed to capture a gull, although once he plucked out a handful (or rather a mouthful) of feathers, probiably the clearness of water and sky was against him, ind the birds saw him in time to escape his jaws. At deey. question naturally arises, How did the seal acquire this art of decoying? It cannot be called instinct. That would have led him to devour the duck as soon as
captured. Did his parents teach him the art? Did he captured. Did his parents teach him the art? Did he decoys in his presence? Or did he invent the process

say " a gourd, and wading out among water fowl to seize
them, and the historic fox, with a bunch of moss in
his mouth, swimming out among them, for the same his mouth, swimming out among them, for the same purpose, are

The damage done by seals to the Canadian salmon fisheries is enormous, and the quantity of fish con-
sumed by them on the coast of Maine is beyond computation; but it is safe to say that each seal cor a greater quantity of fish than does any fisherman's
family in the State, and the total weight of fish consumed by seals on that coast must be many thousand tons. It may well be questioned if it is not an expensive luxury for the State to proh Delicious as seal meat is rep

judges to be, our people still prefer fy competent judges to be, our people still prefer fish upon their
tables, and it is an open question which it is best to protect, the seal or the fish. The seal can take care of Maine, and not until our people learn his value as mination.

One fact in the history of seals has never been satisfactorily explained, viz., their habit of swallowing good-sized pebbles, sometimes in large quantities. The lishermen believe it is done to increase their specific
gravity, or, as they put it, so that they can dive deeper gravity, or, as they put it, so that they can dive deepe
and easier, and claim that the fatter the seal is, and the deeper the water where he is feeding, the mor pebbles will there be found in his stomach.

Many naturalists say that the stones are swallowed dus operandi they neglect to explain, and so shall I. Do the naturalists nean that the pebble in the stomby the gravel in the gizzard of a fowl, and aids in grinding up the shells of mollusks and crustacea, such as leeds at times" crabs, and lobsters, on all which the sea theory of the fishermen.

[Continued from suppos

YEAST: ITS MORPHOIJOGY AND CULTURE.* By A. Gordon Saliamon, A.R.S.M., F.I.C., F.C.S. LECTURE I-CONTINUED.

By far the greater number of species are, however developed by means of asci; an ascus being a large oped within the ascus, and are then known as ascospores. This term possesses an especial significance for us because it has been shown that yeast may be caused
to develop ascospores, and advantage has been taken to develop ascospores, and advantage has been taken valuable system of yeast analysis.
valion the the

It will be shown that this method places it within the power of the brewer not only to determine the exct composition of the yeast with which he is working,
but also to secure the propagation of a species of yeast * Lectures before the Society of Arts, London, 1888. From the Joornal
of the Society. Fun

he purity of which is unquestionable. It has, however done more than this. It has determined the position put an end to the series of arguments wherewith it wa ought to prove that the various yeasts did not reprecycle of development of a more highly organize group. Thus it was stated, by those who were infected with what De Bary terms "the pleomorphic craze, that yeast, when grown in saccharine fluids, would ex if eaten by flies, it would develop in them the germs o the insect fungi or entomopthora ; that these might complete their development as insect fun these migh might also develop into mucor or into achyla (saproleg niea) if the filies fell into water. Finally, it wa asserted that mucor placed in saccharine fluids would esult in its transference into saccharomyces, and thus the pleomorphic cycle was completed. These statements, which were based upon inaccurate experiments, mischievous theory of fermentation, of which Fremy was the leading and certainly the most logical Fremyent. The complete study of the ascospore formation of yeast, as carried out by Reess and Hansen, has absolutely dissipated these erroneous views, has placed the question of yeast culture upon an entirely new
basis, and has, moreover, rendered possible, and indeed probable, the realization of some of the most highly It would be impossible, within the limits of these lectures, to do more than glance at the intricate ques tions connected with general fungology. For more de-
tailed study the reader is referred to the worlks of IDe Bary and Berkeley. I need searcely apologize for stat the pages of the former most of my information from done so would have been to risk inaccuracy and to have ignored the greatest authority upon the subject. The appended classification is compiled from his book and may serve to show the relationship of yeast to other familiar fungal forms, in so far as they are at present regarded by the highest authorities

Now we have seen how the development of ront and merging into one thallus is effected. In the same way it is to be expected that mycelium and sporophore should

Thallophytes which have no chlorophyl

Groups:

I SERIES OF THE ASCOMTCETES

| Phycomycetes

So called because of close ap
proxination to the algæ.

2. DIVBRGENT ASCOMTCETE OF DOIBTFTI, Considered in connection with

\section{Protomyces and Ustilaginex:}

Peronosporea : Some live on the bodies of dead animals and plants; the greater number as ization by male and female organ Ancylisteæ: Parasites are fresh water algæe closely related to peronosporeæ. ronoblepharis : Incomple

2. Saprologeniex: Closely resemble peronosporex live on dead organic bodies in water, mostly of large growth ; male sexual organs wanting, or do
not perform fertilizing functions; spores in motile state when young issue from sporangium.

3. Mucorini : Plants of the dry land; mostly grow on dead organic bodies, especially animal excrement some parasitic on other mucorini, closely connectfer in forming zygospores and onidia. Subdivi(a) Mucoreæ : Spores found endogenously in ter(b) Chætocladieæ: Spores abjointed acrogen(c) Piptocephalideæ: Spores formed acrogen ously and serially by-cross septations.

4. Entomopthoreæ: Penetrate the cavities of bodie of living insects and there develop; form gonidio phores on hyphal branches; make their way and complete their development on its outer surface.

5. Ascomycetes : Composed of branched hyphr; al ways septate; all form spores in asci ; the ase lected together into hymenia.

(a) Ascomycetes bearing apothecium.

(b) Ascomycetes bearing perithecium. by rupturing cell wall.

6. Uredinere : Closely allied to ascomycetes ; all parasites or living phanerogams and ferns ; many complete their development on one host; others order to arrive at certain stages of their develop-

7. Chytridieæ : Microscopic ; mostly live under water swarm spores formed in spora
divisions: 1. Rhizidiex.

$$
\begin{aligned}
& \text { 2. Cladochytriea. } \\
& \text { 3. Olpidex. } \\
& \text { 4. Synchitriex. }
\end{aligned}
$$

intercellular spaces of ustibelliferous plants.

gamous plants ly developed group proceeding from the chy

9. Doubtful Ascomycetes : Laboulbeniece-gro : Exoascus-parasitic on the surface of parts of Saccharomyces-TEAST.* 